\title{
Peer Review of "Forecasting the COVID-19 Pandemic in Saudi Arabia Using a Modified Singular Spectrum Analysis Approach: Model Development and Data Analysis"
}

\section{Anonymous Reviewer}

\section{Related Articles:}

Preprint: https://preprints.jmir.org/preprint/21044

Author Responses to Peer-Review Reports: https://med.jmirx.org/2021/1/e28742

Published Article: https://med.jmirx.org/2021/1/e21044/

(JMIRx Med 2021;2(1):e28741) doi: 10.2196/28741

\section{KEYWORDS}

COVID-19; prediction; singular spectrum analysis; separability; eigenvalues; Saudi Arabia

This is a peer review submitted for the paper "Forecasting the COVID-19 Pandemic in Saudi Arabia Using a Modified Singular Spectrum Analysis Approach: Model Development and Data Analysis".

\section{Round 1 Review}

The paper is very interesting and very timely. I would suggest publishing it after minor revision.
Some information on the singular spectrum analysis technique could be added. Some additional information on COVID-19 cases could also be provided.

When one model outperforms another, it should be statistically tested. Considering the explanation of various parts as well as forecasting error, it is advisable to use a test that does not depend on the normality of error as well as h-step ahead forecasting.

\section{Reference}

1. Alharbi N. "Forecasting the COVID-19 Pandemic in Saudi Arabia Using a Modified Singular Spectrum Analysis Approach: Model Development and Data Analysis. JMIRx Med 2021 Mar 31;2(1):e21044 [FREE Full text] [doi: 10.2196/21044]

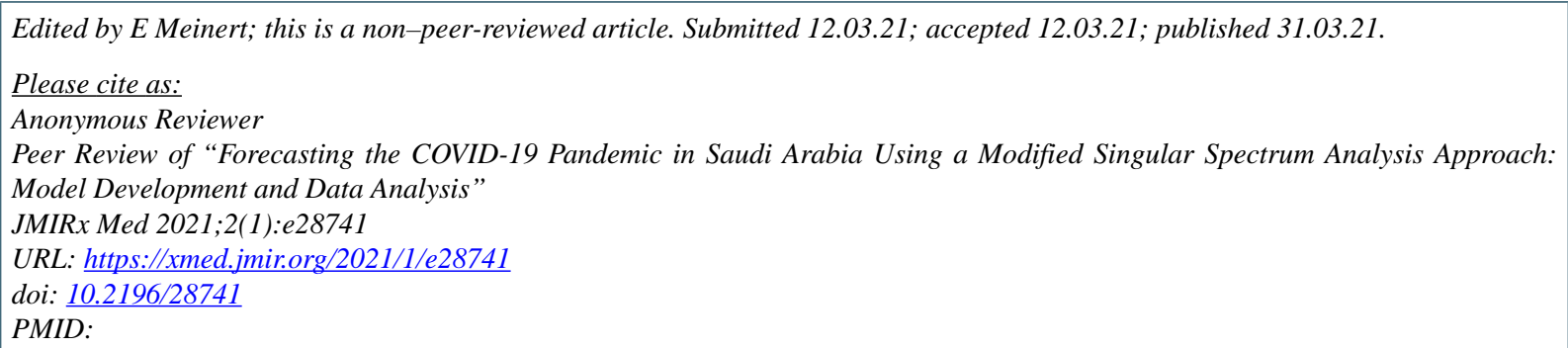

(C) Anonymous Reviewer. Originally published in JMIRx Med (https://med.jmirx.org), 31.03.2021. This is an open-access article distributed under the terms of the Creative Commons Attribution License (https://creativecommons.org/licenses/by/4.0/), which permits unrestricted use, distribution, and reproduction in any medium, provided the original work, first published in the JMIRx Med, is properly cited. The complete bibliographic information, a link to the original publication on https://med.jmirx.org/, as well as this copyright and license information must be included. 